\title{
Decomposition of Valence and Paradox
}

\author{
of Primary Election*
}

Norman Abjorensen $^{\dagger} \quad$ Yusaku Horiuchi $^{\ddagger} \quad$ Meg Sato $^{\S}$

First Draft: May 12, 2011

Last Updated: July 29, 2011

*An earlier draft was presented at the 40th Australian Conference of Economists 2011 (Canberra, Australia; July 11-13, 2011). We appreciate useful comments from Kazuya Kamiya, Hiroshi Osano and other participants of the conference. The authors are listed in alphabetical order, as this paper is in every way a collaborative project.

†Visiting Fellow, Crawford School of Economics and Government, the Australian National University. Tel: +61.(0)2.6125.8584, Email: norman.abjorensen@anu.edu.au.

${ }^{\ddagger}$ Associate Professor, Crawford School of Economics and Government, the Australian National University. Tel: +61.(0)2.6125.4295, Email: yusaku.horiuchi@anu.edu.au.

$\S$ Postdoctoral Fellow, Crawford School of Economics and Government, Crawford School of Economics and Government, the Australian National University. Tel: +61.(0)2.6125.7247, Email: meg.sato@anu.edu.au. 


\begin{abstract}
When does a political party decide to hold a primary election to choose a candidate for the next election, and when does an incumbent decide to announce his/her political retirement? Furthermore, if they make decisions interactively, how do their decisions affect the quality - "valence" - of the candidate who ends up running for the party? In this paper, we examine these questions by modeling a simple strategic game between a party and an incumbent in the context of Australia where political parties take important roles in selecting candidates and making policies. Specifically, by decomposing the valence into three factors, we show that primary elections may facilitate (potentially) high-quality incumbents to retire unexpectedly. We call it a "paradox of primary election." We also show that primaries do not always bring benefits not only to parties but also to society.
\end{abstract}




\section{Introduction}

Much like firms in economic markets, political parties make important decisions on "personnel" matters - recruiting candidates and firing substandard incumbents (or encouraging them to retire). ${ }^{1}$ Although such matters are relevant to political parties in any country, previous studies on candidate selection and de-selection have almost exclusively focused on the cases of the United States (e.g. Carson 2005, Carson, Engstrom \& Roberts 2007, Gerber \& Morton 1998, Kenney \& Rice 1987) or Latin America (e.g. Carey \& Polga-Hecimovich 2006, De Luca, Jones \& Tula 2002, Kemahlioglu, Weitz-Shapiro \& Hirano 2009), where primary elections are well institutionalized or have become increasingly popular. By contrast, political parties in most other countries do not hold primary elections, select only some candidates through primaries, or consider introducing a competitive candidate selection process. With few comparative studies (for exceptions, see e.g., Gallagher \& Marsh 1988), we do not yet fully understand how different institutional settings affect parties' personnel strategies and incumbents' retirement decisions and, more importantly, how they facilitate parties to nominate and retain high-quality candidates.

In this paper, we aim to contribute to the budding literature on comparative analysis of candidate selection process, by focusing on Australia where parties play important roles in selecting candidate (specifically, in deciding whether to hold primary elections), ${ }^{2}$ and in

\footnotetext{
${ }^{1}$ There is another important aspect of a party's personnel strategies, which is related to the process of allocating party/government posts among incumbents, but it is outside the scope of this paper.

${ }^{2}$ In Australia, an intra-party election to choose a candidate running for the next election is called preselection, but we use the conventional term used in the literature.
} 
making policies. ${ }^{3}$ Specifically, by modeling a simple strategic game between a party and an incumbent, we examine the following questions. When does a political party decide to hold a primary election to choose a candidate for the next election, and when does an incumbent decide to announce his/her political retirement? If they make decisions interactively, how do their decisions affect the quality of the candidate who ends up running for the party?

The previous literature has paid limited attention to when and why political parties choose to hold primary elections to select their candidates, but a notable exception is a recent work by Serra (2011). ${ }^{4}$ In this paper, a basic decision-making problem for a party leader is whether to select a candidate through an uncompetitive elite nomination process, in which the selected candidate adopts the most preferred policy position for the party leader, or through a competitive primary election, in which the selected candidate adopts the most preferred policy position of the median voter (i.e., the median policy position of party members who vote for nominees). The former is a low cost option with regard to the deviation of the candidate's policy platform from that of the party leader. The latter, however, is assumed to have a greater chance of nominating a high-quality candidate,

\footnotetext{
${ }^{3}$ As we will discuss later, this is an important setting in our model, with which we can ignore the difference in the policy position of a party and that of a candidate and focus on the impacts of the candidate's non-policy attributes ("valence") on the party's choice of candidate selection method and the candidate's retirement decision.

${ }^{4}$ There is an earlier important work by De Luca, Jones \& Tula (2002). The main objective of this paper, however, is to investigate empirical variations in candidate nomination procedures in Argentina, rather than to develop a formal model to explain a party's choice of candidate selection method, which is the primary focus of Serra (2011) and our paper.
} 
a candidate with high "valence" - "skills, assets and resources that candidates need for campaigning" (Serra 2011, p. 23). Given such a spatial voter model, Serra (2011) conducts various comparative statics.

Serra's paper and our paper both analyze the environment in which parties (or party leaders) are motivated to choose candidate selection methods. There is, however, an important difference. ${ }^{5}$ While Serra (2011), as well as other previous studies, treat valence as a mixed bag of everything useful for campaigning, except for candidates' policy factors, we decompose it into three factors - quality-enhancing valence, incumbent candidate advantage, and residual valence. ${ }^{6}$

The quality-enhancing valence is a type of valence that can be enhanced by experiencing electoral competition repeatedly. Specifically, it is accumulated experience of communicating with voters, listening to their policy needs, developing support network, and mobilizing votes in elections. We consider it as an essential feature of quality politicians. Accordingly, by nominating such candidates, parties can not only attract votes but also bring benefits to society once they are elected.

The incumbent candidate advantage is well documented (e.g. Ansolabehere, Snyder \&

${ }^{5}$ There are some other minor differences. For example, while Serra (2011) assumes that potential nominees are passive players with no strategic choice, our model assumes that a candidate (specifically, an incumbent) has several choices to maximize his/her utility. Serra (2011) relates his model to empirical observations in the U.S. and Latin America, but we discuss ours in the context of Australia.

${ }^{6} \mathrm{~A}$ recent paper by Miller (2011) is one of few papers that attempt to decompose valance. He distinguishes a specific aspect of valence - candidates' effectiveness in changing policy from the status quo - from other aspects of valence. 
Stewart 2000, Gelman \& King 1990, Levitt \& Wolfram 1997). It is the comparative advantage of an incumbent vis-à-vis a fresh candidate in mobilizing votes. By distinguishing it from the quality-enhancing valence, the incumbent candidate advantage in our model mainly relates to name recognition among voters, which is not necessarily relevant to the quality of an incumbent as an experienced politician.

The residual valence includes all other random factors of valence (e.g., whether or not a candidate is a celebrity). It is useful for parties to mobilize votes, but as in the case of incumbent candidate advantage, a candidate with the high residual valence is not necessarily a high-quality candidate who can bring benefits to society.

By decomposing valence in this way, our model shows that a party chooses to hold a primary election when the benefit of holding a primary election, which is to improve an incumbent's quality-enhancing valence, exceeds the total cost, which includes a fixed cost and the cost of replacing the incumbent.

The decomposition of valence also allows us to conduct normative analysis. In the literature (e.g., Adams \& Merrill 2008, Serra 2011, Galasso \& Nannicini 2011), there seems to exist a belief that primaries help parties to find and identify high-quality candidates. Our model, however, shows that primary elections may facilitate (potentially) high-quality incumbents (i.e., incumbents who could update quality-enhancing valence by competing in the election) to retire unexpectedly, when there exits information asymmetry with regard to incumbents' post-retirement opportunities. We call it a "paradox of primary election." We also show that (even without the assumption of information asymmetry), primaries do not always bring benefits not only to parties but also to society. 
The rest of this paper is organized as follows. Section 2 introduces background information to understand and model the process of candidate selection in Australia. Section 3 introduces our game theoretical model and deduces theoretical propositions. The final section concludes and discusses a normative implication and avenues for future research.

\section{Candidate Selection in Australia}

In this section, we first introduce institutional and historical backgrounds relevant to candidate selection and de-selection in Australia. Next, we emphasize the central role of political parties in Australia, an important building-block in our formal model.

\subsection{Backgrounds}

The Australian federal system is, with some exceptions, bicameral in its parliamentary design. The population of 22 million is spread over nine jurisdictions, which include the Commonwealth, the six states (former colonies), and two territories. Typically, most seats in all levels of elections are contested by candidates from two large political camps - the Australian Labor Party (ALP) and the coalition of the Liberal Party of Australia and the Nationals (National Party of Australia) - and governments are formed by majorities in popularly-elected lower houses. Importantly, because of the relatively small size of the chambers and the voting system used for their election, which we will explain shortly, governments almost invariably have to work with small majorities or, as has been the case in recent times, as minority governments with cross-bench support. 
Historically, this has meant that party discipline in Australia is stronger than, say, in the United Kingdom where larger numbers and generally bigger majorities offer some latitude for dissenting votes. In Australian parliaments, this is not the case, and instances of politicians "crossing the floor" - that is, voting against their own party in a parliamentary division are relatively rare and are always attended by publicity. To ensure party discipline, political parties are particularly careful when selecting candidates amenable to party discipline. The ALP, for example, insists that its candidates should sign a "pledge" that binds them to the party's majority decisions on pain of expulsion. ${ }^{7}$

Another key factor relevant to candidate selection in Australia is the system of preferential voting, the single-member Alternative Vote (AV), which is based on the principle of a winner requiring a minimum of $50 \%+1$ support. The system allows voters to number all candidates in order of preference, and if an absolute majority has not been achieved in the first ballot of primary votes, the lowest-ranking candidate is eliminated and his or her preference votes are distributed. This process continues until a candidate achieves an absolute majority. 8 The dynamics of this system must be taken into consideration when parties take decisions on candidate selection. Candidates who have failed to gain official endorsement may choose to stand for election as an independent candidate. Thus, they may

\footnotetext{
${ }^{7}$ For example, see the nomination form (including the parliamentary candidate's pledge) prepared by the ALP's Western Australian Branch (available at http://www.wa.alp.org.au/download/candidates_ nomination_form_1.pdf, accessed on July 28, 2011). All state and territory branches have a similar provision.

${ }^{8}$ For a more detailed explanation, see Sawer, Abjorensen \& Larkin (2009, p. 114).
} 
draw support away from their former party either through attracting primary votes of their own, or directing their preferences (i.e., their secondary votes, tertiary votes,...) to a rival party/candidate, or both.

Once a candidate is pre-selected and then elected to a parliament, either state or federal, the immediate task for the sitting member is to secure his/her incumbency against challenge. Generally, a sitting Liberal member enjoys greater security than a Labor member, owing to a lower level of party activism and a lesser intensity of factional wrangling. Chief among factors that can disrupt incumbency is an exogenous redrawing of electoral boundaries. ${ }^{9}$ This brings in to play both a different set of internal party dynamics, as well as a shift in the dominant demographics of the district. ${ }^{10}$ For example, an incumbent enjoying support from a district with a high proportion of aging voters might be seen as less effective if the district boundaries shift to include vast areas from a formerly adjacent district that includes high numbers of younger voters.

The last, but not the least, important aspect in the pre-selection process in Australia is the pressure brought on incumbents by means of "branch stacking" - that is, the mass recruitment of new party members in the local area for the sole purpose of forcing a preselection ballot (Allan 2002). This can often have the effect, as in the case of Bob Sercombe

\footnotetext{
${ }^{9}$ Redistricting is prepared and determined by an independent, nonpartisan committee. It is important to note that redistricting is relatively frequent in Australia. Horiuchi \& Sato (2010) introduce the natures of electoral redistricting in Australia, and examine its impacts on candidate selection.

${ }^{10}$ An electoral district is called an "electoral division" or "electorate" in Australia, but we use the conventional term.
} 
described later, of forcing an incumbent to retire rather than to face a contest in which the numbers were stacked heavily against them.

\subsection{Parties in the Australian Context}

It is difficult to overstate the importance of political parties in the Australian political process. As Jaensch (1983) argues, politics in Australia is party politics and government is party government. At every level of the federal system, political parties contend for office: They develop policies and mediate among interest groups; they serve to articulate concerns of civil society; and they recruit and train elites for public office. The adversarial nature of political life in Australia brings with it a high measure of accountability through scrutiny, criticism and debate in which the parties are the primary vehicles.

Just as political competition between the parties remains intense, so does political competition within parties among both individuals and factions vying for favor and influence. Nowhere is this more in evidence than in the process of candidate selection. The relationship of each candidate to a party is highly interdependent and the competition among (potential) candidates is intense: As most voters identify with parties rather than individual candidates, candidates need party endorsement along with administrative support and financing to have any chance of either winning or retaining a seat, whereas the party needs capable candidates to represent its policies and attract electoral support. Therefore, the party is in fact the immediate and primary "constituency" of a candidate; especially an incumbent. Without the continuing confidence of that constituency, an incumbent will face challenge. That was indeed the fate of former Labor Prime Minister, Kevin Rudd, who was 
removed from office, not by the electorate but by his own party, in June 2010.

An incumbent facing challenge has three options: one is to enter the primary-election ballot and seek retention of his or her party endorsement; two is to retire in the face of challenge; and three is to seek to retain his/her parliamentary seat by contesting the election as an independent candidate. We will incorporate these options and calculus in our model.

In the case of selecting candidates for lower houses at both state and federal levels, local party branches are dominant in the process (Jaensch 2006, 36-41). They seek candidates who satisfy factional power alignments within the branches and who possess qualities of strong electoral prospects, media attention and the ability to represent a local constituency. A decision by a panel of party members, usually representing both the local branch and the central party office (and in the case of the Labor Party, affiliated unions) is usually the way in which pre-selections are decided. ${ }^{11}$

\section{A Game Theoretical Model}

In this section, given the Australian political contexts we introduced in the previous section, we present a game theoretical model and analyze when and how a party holds a primary election and an incumbent retires, and how candidates' attributes affect the party and the incumbent's decisions.

\footnotetext{
${ }^{11}$ In terms of candidate selection and de-selection, there has been an increasing tendency towards centralization in party head offices, more marked in the ALP than the Liberal Party (Jaensch 2006, 26-27). This tendency, however, does not affect the basic setting of our model.
} 


\subsection{Elections, Players, and Stages}

There are two different types of elections in our game - primary and general elections. The former is an intra-party process to choose a candidate, while the latter is a process to choose representatives to a legislative assembly. ${ }^{12}$ In Australia, only party members are usually eligible to vote in primary elections. In general elections, voting-age citizens who register on the electoral roll can vote. ${ }^{13}$ Each electoral district has one seat, for which two candidates from the two major parties typically compete. As introduced in the previous section, however, there is a possibility that a "third" candidate - an independent or a candidate from a small party - becomes a viable competitor for the two camps. ${ }^{14}$ This possibility is an important consideration for party leaders, and thus we must take it into account in our model.

The game has two players and three stages, and its extensive form (i.e., a game tree) is presented in Figure 1. In the first stage, Player 1 (a party) chooses an action $a_{1}$ from the action space $A_{1}=\{P, N, I\}$; namely, it decides whether to hold a primary election $(P)$, to field a $\underline{n}$ ew candidate for an upcoming general election without holding a primary election $(N)$, or to field an $\underline{i}$ ncumbent candidate for a general election without holding a primary election $(I)$. An implicit assumption here is that a party takes a strong initiative in the

\footnotetext{
${ }^{12}$ Our model is also applicable in a setting where a party chooses its candidate for a by election, which is a process to fill a vacant position in an assembly.

${ }^{13}$ Voting is compulsory in Australia, but this institutional feature is irrelevant in our model.

${ }^{14}$ In reality, there are some other candidates from minor parties in each district, but as they have almost no chance of winning a seat, we ignore such minor candidates.
} 


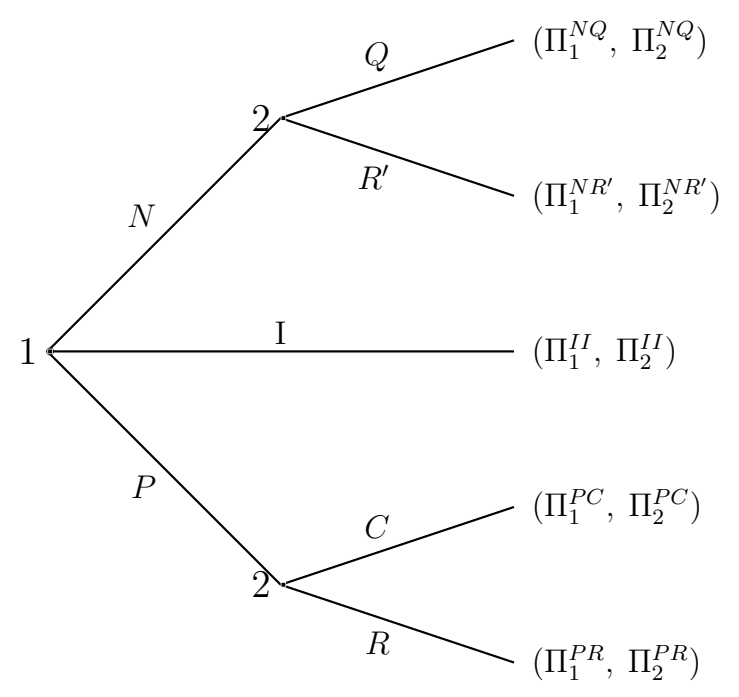

Figure 1: A Game Tree.

candidate selection process. ${ }^{15}$ As we discussed in the previous section, this is indeed the case in the Australian political context.

In the second stage, after observing $a_{1}$, Player 2 (an incumbent) chooses an action $a_{2}$. If Player 1 decides to hold a primary election $\left(a_{1}=P\right)$, then an action Player 2 can take is either to $\underline{c}$ ompete in the primary election $(C)$ or to $\underline{r}$ etire without competing against an alternative candidate from the same party $(R)$. If Player 1 decides to bring in a new candidate for a general election without holding a primary election $\left(a_{1}=N\right)$, then, an action Player 2 can take is either to quit the party and run for the general election as an

\footnotetext{
${ }^{15}$ There are cases in which a party decided to hold a primary election after an incumbent had retired. We consider, however, a more common situation in which an incumbent seeks re-election and a party has three options to select a candidate. We also note that in reality, there should exist "under-the-table" negotiations before a party makes its decision on how to select a candidate. This can be considered to be occurring in Stage 0 before Stage 1 in this game.
} 
independent candidate $(Q)$ or to $\underline{r}$ etire $\left(R^{\prime}\right)$. Unlike the case of retirement after Party 1's announcement to hold a primary election $(R)$, this retirement $\left(R^{\prime}\right)$ can be considered forced retirement, because an incumbent has no choice to stay within a party if he/she intends to keep office in an assembly. Finally, if Player 1 asks Player 2 to run for a general election, for simplicity, we assume that Player 2 accepts the offer; namely, there is no choice set for Player 2 if $a_{1}=I$.

In the third (final) stage, payoffs to Players 1 and 2 are realized. Before we discuss the payoff for each set of strategic choices by the players, we need to introduce a crucial element in our formal model, which is the decomposition of valence.

\subsection{Decomposition of Valence}

In general, the probability that a candidate wins a seat in an election is a function of policy factors and non-policy factors. The policy factors are relevant to a candidate's policy positions on issues at stake and his/her concrete policy proposals. In the Australian context, however, the party is much stronger than individual candidates in making policies, as noted earlier. Thus, we can ignore a potential small variation in policy factors among candidates (i.e., an incumbent and a new candidate) within the same district (i.e., the same distribution of policy preference among voters) from the same party.

This allows us to focus on non-policy factors that may affect one's winning probability. In the literature, the general term for such factors is "valence" (for recent studies, see e.g. Galasso \& Nannicini 2011, Miller 2011, Serra 2011). Previous studies, which tend to focus on the roles of policy factors, assume that valence as an all-inclusive "other" factor a candidate 
can take advantage of in mobilizing votes. In our model, however, we shed more light on the valence itself, decompose it into three elements, and study their impacts on candidate selection and political retirement.

The first element of valence (expressed by $\alpha_{i}$ ) is a candidate's quality that can be enhanced by the number of times he/she competes in primary and/or general elections. We call it quality-enhancing valence. It corresponds to each candidate's skills and resources, which can be shaped and accumulated through experience of communicating with voters and other stake holders, developing networks of core supporters, and raising campaign funds. Since such accumulated experience enhances incumbents' capability in listening to and responding to supporters' interests and needs, quality-enhancing valence is beneficial not only to parties in attracting votes but to society.

The subscript of $\alpha_{i}$ denotes the number of times a candidate will have competed by the time a general election is held. Specifically, $i=0$ if a new candidate will run for a general election without competing in a primary election. If an incumbent re-runs for an upcoming election without going through a primary election, $i=1 .{ }^{16}$ It is also $i=1$ if a new candidate competes against an incumbent and wins in a primary election. Finally, if an incumbent competes in a primary election and wins candidacy for an upcoming general election, then

\footnotetext{
${ }^{16}$ For simplicity, we assume that incumbents have the same level of quality-enhancing valence in the first stage, irrespective of the number of times they won in the past. This assumption is not out of touch with reality, because of the frequent and exogenous redrawing of electoral boundaries in Australia. (Also see Footnote 9.) Even repeatedly elected incumbents must face "new" voters after redistricting and their quality-enhancing valence is discounted.
} 
$i=2$.

An important assumption is that a candidate's "true" election-enhancing valence whether he/she is $\underline{t}$ alented $\left(\beta_{T}\right)$ or $\underline{s u b s t a n d a r d}\left(\beta_{S}\right)$ - is exogenously given and that a party and a candidate himself/herself both do not know it until it is Bayes' updated. If a candidate, who ends up running for a general election, will have had no experience of competing in any intra-party or inter-party election, both players assume that such a new candidate is talented with a $50 \%$ probability. Formally,

$$
\alpha_{0} \equiv \frac{1}{2}\left(\beta_{T}+\beta_{S}\right)
$$

This means that there is an equal chance that the new candidate is talented or substandard.

If a candidate (either an incumbent or a new candidate) is selected to run for a general election by experiencing only one (primary or previous general) election, Players' subjective prior probability that the candidate is talented is greater than $50 \%$. Their guess is better than a mere random conjecture, because winning a seat in the previous election (in the case of an incumbent) or winning a nomination for the next general election (in the case of a new candidate) is a useful piece of information for them to update their belief about the candidate's ability (Serra 2011). In other words, the candidate reveals his/her electionenhancing valence, at least partially, by experiencing electoral competition. Formally, this subjective probability is $\gamma^{T}>\frac{1}{2}$, where $\gamma^{T}>\gamma^{S}$ and $\gamma^{T}+\gamma^{S}=1$. Therefore, in this case, Players assume that the candidate's election-enhancing valence is:

$$
\alpha_{1} \equiv \gamma^{T} \beta_{T}+\left(1-\gamma^{T}\right) \beta_{S}
$$

Finally, if an incumbent competes in a primary election (i.e., if the incumbent will have 
won twice - in the primary election and in the past general election - by the time the next general election is held), we assume that the primary election helps reveal the incumbent's true ability - If he/she wins (loses), he/she is talented (substandard) with probability one. Then, the expected level of election-enhancing valence of an incumbent candidate if he/she wins a primary election is updated to:

$$
\alpha_{2} \equiv \beta_{T}
$$

For the sake of simplification, we assume that the true ability is fully revealed when an incumbent competes in a primary election. The main result of this paper is the same if we assume that a primary election further updates the subjective probability distribution of an incumbent's true ability, as long as $\alpha_{0}<\alpha_{1}<\alpha_{2}$ holds.

The second element of valence is well-known incumbent candidate advantage, denoted by $v$. If a candidate is an incumbent, $v>0$. If he/she is a new candidate, $v=0$. Once a candidate is elected, he/she obtains name recognition or credentials as a politician. The difference between quality-enhancing valence and incumbent candidate advantage in this paper is that the latter is constant regardless of how much a candidate accumulates his/her experience as a politician through competition within and between parties. Therefore, we assume that this element of valence is useful for the party to mobilize votes but do not necessarily bring social benefits.

The third element of valence is what we call residual valence, denoted by $\theta_{k}$, where $k=N$ if a candidate is a new candidate, and $k=I$ if a candidate is an incumbent. It includes all remaining factors relevant for a party when mobilizing votes. For example, if 
a candidate is a celebrity, he/she will have large $\theta_{K}$. If a candidate is involved in some scandals, $\theta_{K}$ becomes small. Such residual or random factors are by definition related to neither candidates' experience as a politician nor the status of incumbency. Therefore, we assume that mobilizing votes by appealing residual valence brings no social benefit.

\subsection{Payoffs to Players}

The payoff to a party (i.e., Player 1) is a function of the exogenous benefit of winning a seat in a general election $(\pi>0)$, the endogenous probability of winning the seat $(p)$, and the exogenous cost of holding a primary election $(c>0)$. The probability $p$ depends on the combination of actions Player 1 and Player 2 choose. Thus, formally, Player 1's payoff is expressed as follows: for $a_{1} \in\{P, N\}$ and an action $a_{2}$ chosen in the second stage,

$$
\Pi_{1}^{a_{1} a_{2}}= \begin{cases}p\left(a_{1}, a_{2}\right) \pi-c & \text { for } a_{1}=P \text { and } a_{2} \in\{C, R\} \\ p\left(a_{1}, a_{2}\right) \pi & \text { for } a_{1}=N \text { and } a_{2} \in\left\{Q, R^{\prime}\right\}\end{cases}
$$

and for $a_{1}=I, \Pi_{1}^{I I}=p(I) \pi{ }^{17}$

The payoff to an incumbent (i.e., Player 2) is expressed by $\Pi_{2}^{a_{1} a_{2}}$ and it also depends on the combination of actions Player 1 and 2 choose. Each is a function of utility (or utilities) attached to a specific outcome (or potential outcomes). It is $U_{W}>0$ if a candidate wins in a general election (with or without competing in a primary election), and $U_{L}$ if he/she loses

\footnotetext{
${ }^{17}$ When Player 1 has chosen to field an incumbent for the general election $\left(a_{1}=I\right)$ without holding a primary election, Player 2 has no choice; namely, Player 2 is running for the general election. To be consistent with other notations, however, we denote the expected payoffs as $\Pi_{1}^{I I}$ and $\Pi_{2}^{I I}$, rather than $\Pi_{1}^{I}$ and $\Pi_{2}^{I}$.
} 
in the primary election (and thus loses an opportunity to run for the general election) or in the general election (with or without competing in the primary election). For simplicity, we assume $U_{L}=0$ regardless of which type of an election an incumbent loses.

For Player 2, there are two types of retirement. One is when Player 2 has a choice to stay within a party after the party announces its intention to hold a primary election. The reservation utility for this type of retirement is expressed by $U_{R}$. The other is when Player 2 does not have a choice to stay within a party after the party announces to nominate a fresh candidate without holding a primary election. Its reservation utility is expressed by $U_{R^{\prime}}$. As noted earlier, the latter is equivalent to "forced" retirement and hence the utility of an incumbent should be smaller than the former case, $U_{R}>U_{R^{\prime}}$.

Finally, we assume $U_{W}>U_{R}>U_{L}$. The best outcome for an incumbent is to maintain his/her seat in the parliament. If that is not possible, he/she prefers voluntary retirement (often by claiming that he/she makes way for a younger candidate) as compared to losing in an election. The former is more likely to build positive reputation and image among supporters and may help the incumbent find a post-retirement job.

Given these assumptions, there are five combinations of expected payoffs to Player 1 and Player 2, and they are expressed as follows. (Also see Figure 1.) We start with the case in which Player 1 decides to hold a primary election $(P) .{ }^{18}$ If Player 2 decides not to compete in the primary election, he/she retires $(R)$ and Player 1 fields a new candidate. Expected

\footnotetext{
${ }^{18}$ One of the main costs of a primary election is the cost for a party to search a new candidate. Therefore, even when an incumbent decides to retire after a party has decided to hold a primary election (i.e., has found an alternative candidate), the party incurs the costs.
} 
payoffs to Player 1 and Player 2 are represented by

$$
\left(\Pi_{1}^{P R}, \Pi_{2}^{P R}\right)=\left(\left(\alpha_{0}+\theta_{N}\right) \pi-c, U_{R}\right)
$$

The payoff to Player 1 is a function of the probability that the new candidate (without experiencing any competitive process) wins in a general election, $\left(\alpha_{0}+\theta_{N}\right)$. If Player 2 decides to compete in the primary election $(C)$, expected payoffs are

$$
\left(\Pi_{1}^{P C}, \Pi_{2}^{P C}\right)=\left(\left[\delta\left(\alpha_{2}+v+\theta_{I}\right)+(1-\delta)\left(\alpha_{1}+\theta_{N}\right)\right] \pi-c, \delta\left(\alpha_{2}+v+\theta_{I}\right) U_{W}\right)
$$

where $\delta$ is the probability of Player 2 winning the primary, and is exogenously given. The probability that an incumbent wins in the primary and general elections is $\delta\left(\alpha_{2}+v+\theta_{I}\right)$, while the probability that a new candidate wins both is $(1-\delta)\left(\alpha_{1}+\theta_{N}\right)$.

Next, we describe expected payoffs to both players when Player 1 decides to field a new candidate for a general election $(N)$ without holding a primary election. In this case, Player 2 either retires $\left(R^{\prime}\right)$ or quits the party and runs as an independent candidate $(Q)$. The expected payoffs are represented by

$$
\left(\Pi_{1}^{N R^{\prime}}, \Pi_{2}^{N R^{\prime}}\right)=\left(\left(\alpha_{0}+\theta_{N}\right) \pi, U_{R^{\prime}}\right)
$$

and

$$
\left(\Pi_{1}^{N Q}, \Pi_{2}^{N Q}\right)=\left(\left[\left(\alpha_{0}+\theta_{N}\right)-\left(\alpha_{1}+v+\theta_{I}\right)\right] \pi,\left(\alpha_{1}+v+\theta_{I}\right) U_{W}\right)
$$

respectively. When Player 2 runs as an independent, Player 1 must field a new candidate who must compete against this independent candidate, as well as a candidate from the other party. For simplicity, we assume that the independent candidate (i.e., the incumbent) takes 
all of his/her votes from the new candidate ("cracking-vote"). ${ }^{19}$ Thus, the probability that a new candidate wins in the general election is $\left(\alpha_{0}+\theta_{N}\right)$ minus $\left(\alpha_{1}+v+\theta_{I}\right)$.

We assume $\Pi_{2}^{N R^{\prime}}<\Pi_{2}^{N Q}$, because the forced retirement of Player $2\left(R^{\prime}\right)$ is neither Player 2 had planned nor he/she expected and thus is the worst possible outcome for Player 2. This type of retirement does not help an incumbent to develop good image among supporters, which is expected to be useful when he/she searches for post-retirement career. Thus, we assume that an incumbent, who is dissatisfied with a party's decision to replace him/her with a new candidate, always chooses to run as an independent.

The last possible outcome of a game is when Player 1 decides not to hold a primary election and asks Player 2 to run for a general election $(I)$. In this case, the combination of expected payoffs are described as

$$
\left(\Pi_{1}^{I I}, \Pi_{2}^{I I}\right)=\left(\left(\alpha_{1}+v+\theta_{I}\right) \pi,\left(\alpha_{1}+v+\theta_{I}\right) U_{W}\right),
$$

The probability that an incumbent gets re-elected without competing in a primary election is $\left(\alpha_{1}+v+\theta_{I}\right)$.

\subsection{Sub-game Perfect Nash Equilibrium}

In this section, we solve the game and introduce two theoretical propositions and a corollary. Section 3.4.1 discusses the case with symmetric information, while Section 3.4.2 examines the asymmetric information case.

\footnotetext{
${ }^{19}$ The main result of this paper is the same if we assume that the independent takes votes from both the new candidate and the candidate from the opponent party.
} 


\subsubsection{No Asymmetric Information on $U_{R}$}

We start with a simple case with no asymmetric information between two players with regard to $U_{R}$; namely, a party (Player 1 ) and an incumbent (Player 2) both know the incumbent's utility level when he/she retires without competing in a primary election.

If $U_{R}$ is sufficiently large and Player 2 chooses to retire if Player 1 intends to hold a primary election, fielding an incumbent candidate without a primary election is usually a dominant strategy for Player $1 .^{20}$ As this situation does not reflect the reality in Australia where primary elections are selectively held, we assume $U_{R}$ to be sufficiently small so that Player 2 decides to compete in a primary election if Player 1 decides to hold it. Formally, we assume $\Pi_{2}^{P R}<\Pi_{2}^{P C}$, thereby the following condition must be satisfied:

$$
\delta \geq \frac{U_{R}}{\left(\alpha_{2}+v+\theta_{I}\right) U_{w}}
$$

Given this condition, through backward induction, Player 1 decides whether to field an incumbent without holding a primary or letting him/her compete against a new candidate in the primary. Specifically, Player 1 compares $\Pi_{1}^{I I}$ and $\Pi_{1}^{P C} \cdot{ }^{21}$

\footnotetext{
${ }^{20}$ Formally, if $\Pi_{2}^{P R}>\Pi_{2}^{P C}$, Player 1 must compare $\Pi_{1}^{P R}$ and $\Pi_{1}^{I I}$. In this case, $\Pi_{1}^{P R}<\Pi_{1}^{I I}$ holds because $\left[\left(\alpha_{1}-\alpha_{0}\right)+\left(v+\theta_{I}\right)-\theta_{N}\right] \pi+c>0$ holds, unless $\theta_{N}$ is fairly large. Also note that $\Pi_{1}^{I I}>\Pi_{1}^{N Q}$ usually holds (see the next footnote).

${ }^{21} \Pi_{1}^{N Q}$ is smaller than $\Pi_{1}^{I I}$, because $\left(2 \alpha_{1}-\alpha_{0}\right)+2\left(v+\theta_{I}\right)-\theta_{N}>0$ holds unless $\theta_{N}$, a new candidate's residual valence, is fairly large. The case in which this became large was when Peter Garrett was nominated by the ALP for the seat of Kingsford Smith in Sydney. As Garrett was the former rock singer of the band Midnight Oil and a prominent environmentalist, he had a high-profile (large $\theta_{N}$ ). The ALP at that time wished to improve its environmental credentials, especially among young voters who rated environment
} 
This leads to the following Proposition.

Proposition 1 A party (Player 1) decides whether or not to hold a primary election by comparing the total cost of the primary election, which includes a fixed cost of holding it and the cost of replacing an incumbent (Player 2), and the total benefit of the primary election, which is the increment of its expected payoff through the increase in the quality-enhancing valence of the incumbent.

\section{Proof. If}

$$
c+(1-\delta)\left(v+\theta_{I}-\theta_{N}\right) \pi \geq\left(\alpha_{2}-\alpha_{1}\right) \delta \pi
$$

holds, the total cost of holding a primary election exceeds its total benefit. In this case, $\Pi_{1}^{I I}$ is larger than $\Pi_{1}^{P C}$, and Player 1 's action is not to hold a primary election and Player 2 runs for a general election. If

$$
c+(1-\delta)\left(v+\theta_{I}-\theta_{N}\right) \pi \leq\left(\alpha_{2}-\alpha_{1}\right) \delta \pi
$$

holds, the opposite is true, and Player 1 holds a primary election and Player 2 competes against another candidate from the same party.

The right-hand side of (11) and (12) is the total benefit of holding a primary election. With the probability of $\delta$, Player 2 wins the primary, and the expected quality-enhancing protection a high priority. Thus, the party hugely supported Garrett. Unless in very special instances like the case of Garrett, however, parties do not field a fresh candidate without a primary election in Australia. Therefore, for simplicity and to stay focus on our examination of causes and consequences of holding a primary election, we assume $\Pi_{1}^{I I}>\Pi_{1}^{N Q}$. Recall that $\Pi_{2}^{N Q}>\Pi_{2}^{N R^{\prime}}$ is assumed in this paper. 
valence of Player 2 will increase by $\left(\alpha_{2}-\alpha_{1}\right) \cdot{ }^{22}$ Given the exogenous benefit of winning a seat in the upcoming general election $(\pi)$, the right-hand side of (11) and (12) implies the expected increase in the benefit for Player 1 if Player 1 decides to hold a primary election and Player 2 wins.

The left-hand side of (11) and (12) is the total cost of holding a primary election, which is the sum of the fixed cost of holding the primary election $(c)$ and the cost of replacing an incumbent $\left((1-\delta)\left(\theta_{I}+v-\theta_{N}\right) \pi\right)$. If a primary election is held and a new candidate wins with the probability of $(1-\delta)$, Player 1 will lose components of Player 2's valence - incumbent candidate advantage $(v)$ and his/her residual valence $\left(\theta_{I}\right)$. In theory, if a new candidate's residual valence $\left(\theta_{N}\right)$ is large enough to exceed the sum of an incumbent's residual valence incumbent candidate advantage $\left(\theta_{I}+v\right)$, there is no cost of replacing the incumbent. In practice, however, this is uncertain until we observe the result of a general election. Therefore, there is always a risk, for a party, of losing an incumbent when making a decision to hold a primary or not. This result is contrary to a common belief that a primary election is always beneficial for a party as long as its fixed cost is sufficiently small.

An example suggesting the validity of Proposition 1 is the following. The seat of Bradfield, which is on Sydney's affluent North Shore, was one of the safest Liberal seats. For more than twenty years, it had been held by a former diplomat, David Connolly, who in that time had managed to secure only a junior front-bench position despite his popularity in his district. The Liberal Party, which was looking to return to government in 1996,

\footnotetext{
${ }^{22} \alpha_{1}$ is the level of quality enhancing valence if a new candidate competes in a primary election, which is
} the same as its level if an incumbent does not compete in a primary election and runs for a general election. 
was anxious to further improve the quality of this longtime incumbent, and Connolly was challenged in a pre-selection contest, losing to a high-profile candidate - Brendan Nelson, the former head of the Australian Medical Association, who subsequently became a senior minister and later a party leader.

In this example, the party expected that the marginal increase in Connolly's quality enhancing valence would be small given his long political career (i.e., low $\alpha_{2}-\alpha_{1}$ ). Thus, the benefit of holding a primary election was not large. Nelson's profile, however, was very high (i.e., high $\theta_{N}$ ) - presumably higher than the sum of Connolly's incumbency advantage $(v)$ and his relatively low profile (i.e., low $\theta_{I}$ ), which was indeed the party's concern at that time. Therefore, the cost of holding a primary election was perhaps even smaller than the small benefit of holding it. We interpret that the Liberal Party ended up holding the primary after undertaking such a cost-benefit analysis.

We further consider the effect of holding a primary election on social welfare. A key assumption here is that one unit of a candidate's quality-enhancing valence generates the social benefit by $S$, while his/her incumbency advantage and residual valence neither bring any social benefit, as we have already discussed earlier, nor incur any social cost. Then, the social welfare of holding a primary election is the multiplication of the increased qualityenhancing valence of an incumbent if he/she wins $\left(\delta\left(\alpha_{2}-\alpha_{1}\right)\right)$ and $S$, subtracted by the fixed cost $(c)$. If

$$
\delta\left(\alpha_{2}-\alpha_{1}\right) S \geq c
$$


holds, a party 's decision to hold a primary election will bring net benefit. If

$$
\delta\left(\alpha_{2}-\alpha_{1}\right) S \leq c
$$

holds, however, holding a primary election becomes costly for society. Thus, in this case, a party should encourage its own incumbent candidate to run for a general election without holding any primary election. This leads to:

\section{Corollary 1 If}

$$
\frac{c}{\pi}+(1-\delta)\left(v+\theta_{I}-\theta_{N}\right) \leq\left(\alpha_{2}-\alpha_{1}\right) \delta \leq \frac{c}{S}
$$

holds, a party (Player 1) holds a primary election to pursue its own advantage, but its decision is harmful for society.

A case in which this condition holds is when voters discount the benefit of having a candidate with quality-enhancing valence (small $S$, i.e., large $\frac{c}{S}$ ), while a party nominates a celebrity candidate (e.g., a famous former Olympian) with large $\theta_{N}$ as a intra-party rival against an incumbent. In other words, under such a situation of "celebritization" of politics (West \& Orman 2002), holding a primary election may not be socially optimal. Our model formally addresses a negative consequence of this growing tendency in many advanced democracies.

\subsubsection{Asymmetric Information on $U_{R}$}

We now assume that an incumbent's reservation utility of retirement $\left(U_{R}\right)$ has some uncertainty: With the probability of $q, U_{R}$ is higher than $\delta\left(\alpha_{2}+v+\theta_{I}\right) U_{W}$. In this case, the expected payoff to Player 1 is the weighted average of $\Pi_{1}^{P R}$ and $\Pi_{1}^{P C}$. Similarly, the expected 
payoff to Player 2 is the weighted average of $\Pi_{2}^{P R}$ and $\Pi_{2}^{P C}$. These are expressed by

$$
\left(\Pi_{1}^{P \tau}, \Pi_{2}^{P \tau}\right)=\left(\begin{array}{c}
(1-q)\left\{\left[\delta\left(\alpha_{2}+v+\theta_{I}\right)+(1-\delta)\left(\alpha_{1}+\theta_{N}\right)\right] \pi-c\right\} \\
+q\left[\left(\alpha_{0}+\theta_{N}\right) \pi-c\right], \\
(1-q) \delta\left(\alpha_{2}+v+\theta_{I}\right) U_{w}+q U_{R}
\end{array}\right),
$$

where $\tau \in R, C .^{23}$

Furthermore, and more importantly, we assume that the true value of $U_{R}$ is only known to Player 2 but not to Player 1. If Player 1 believes that Player 2's reservation utility $\left(U_{R}\right)$ is small, its subjective probability that Player 2 will retire (once Player 1 announces to hold a primary election) is small (i.e., the small subjective value of $q$ ). If $q$ is perceived to be infinitesimally small, (16) resembles (6). In this case, Player 1 decides its action by simply comparing $\Pi_{1}^{P C}$ and $\Pi_{1}^{I I}$, as in the case we already discussed in Section 3.4.1. Specifically, if (Player 1 believes that) $\Pi_{1}^{P C}$ is larger than $\Pi_{1}^{I I}$, Player 1 decides to hold a primary election with an expectation that Player 2 is highly likely to compete in the primary. If Player 2, however, knows that his/her true reservation utility is sufficiently large, Player 2 may choose to retire, unexpectedly to Player 1's expectation. This leads to:

Proposition 2 If there exists information asymmetry on the reservation utility of retirement, a "paradox of primary election" may arise. Specifically, a party (Player 1) holds a primary election when the expected benefit of enhancing an incumbent's (Player 2's) valence is larger than the expected cost of holding a primary election (as shown in Proposition 1), but Player 2 may choose to retire, unexpectedly to Player 1's expectation.

\footnotetext{
${ }^{23}$ As in Section 3.4.1, we assume that the reservation utility $U_{R}$ is (perceived to be) not so large so that Party 1's decision to hold a primary election can be a feasible outcome. Also see Footnote 20.
} 
In firms, an employee contemplating a job switch does not usually tell his/her employer about outside options (i.e., other job opportunities). Likewise, it is not rare that an incumbent has some private information about the utility arising from his/her outside options. In this case, Proposition 2 suggests that holding a primary election may facilitate a potentially high-quality incumbent - an incumbent who could update his/her quality-enhancing valence by competing against another candidate from the same party in a primary election - to retire unexpectedly. This leaves another candidate, who may be suboptimal for a party, the only remaining choice for the party.

A case suggesting the validity of Proposition 2 is Bob Sercombe who had held the safe Labor seat of Maribyrnong in inner Melbourne since 1996. In 2005, a prominent union leader, Bill Shorten, who had become a national figure in publicity over a dramatic mine rescue, announced that he would challenge Sercombe for Labor endorsement. Initially, Sercombe was determined to contest in a primary election, and the party fully expected him to do so. When it became clear, however, he would suffer a humiliating defeat (i.e., very small $\delta$, which makes $\Pi_{2}^{P C}$ smaller than $\Pi_{2}^{P R}=U_{R}$ ), he withdrew his nomination only days before the scheduled ballot and Shorten was endorsed unopposed. ${ }^{24}$

Our model suggests the following interpretation. Sercombe had reservation utility, which was of a sufficiently high order for him to withdraw from the contest without any significant loss. A former member of the Victorian state parliament, where he had been the deputy leader of the Labor Party, and a four-term member of the federal parliament ensured that he would draw a generous pension. In addition, his shadow portfolio area of expertise, overseas

\footnotetext{
${ }^{24}$ Jason Koutsoukis, "Shorten pushed for federal seat," The Age, May 14, 2006.
} 
development, offered considerable post-politics opportunities, and he eventually set up as an international consultant in that field. The labor party, however, bet on the wrong horse; namely, they expected Sercombe to run for the primary election so that he could update his quality-enhancing valence, with an anticipation - which turned out to be wrong - that the probability of Sercombe having the large reservation utility was small.

\section{Conclusion}

In this paper, with a focus on the political context of Australia, we examined conditions under which a political party decides to hold a primary election and an incumbent retires. When a political party is powerful enough to choose a candidate-selection method by calculating its total costs and benefits, our model suggests what we call a "paradox of primary election" may arise - The end result may not be optimal for the party. Specifically, a candidate who has a post-political-career option (which yields sufficiently high reservation utility, but is unknown to a party) may unexpectedly retire even when the party wants him/her to enhance his/her valence by competing against another candidate in a primary election. Furthermore, by decomposing valence into three components, we also showed that holding a primary election is not always optimal even for society.

If there are two, and only two, options for a party, whether it should always hold a primary election or it should always pick a candidate (an incumbent or a new candidate) without any intra-party selection process, the former is socially better than the latter, as previous scholars implicitly or explicitly assumed. This is because voters will be able to 
vote for a candidate whose quality has been improved (or revealed) through winning in the primary election. But when we look at this in a broader picture and assume that a party has a choice of holding or not holding a primary, residual valence (e.g., whether or not a candidate is a celebrity), which does not necessary bring benefits to society, plays an important part and distorts what primaries are often aimed to do - pick the most capable candidate for a party and society.

Although we developed our model given the Australian context, we believe that our model can be applicable in other countries (with some modification and refinement, if necessary). Indeed, parties in Latin American countries choose between primaries and direct appointments. Even in the United States where primary elections are well institutionalized, as Serra (2011) argues, parties in effect decide whether to choose candidates through contested or uncontested primary elections (Schantz 1980). Developing models of candidate selection and political retirement in other countries, by assuming strategic interactions between parties and candidates as we did in this paper, is an important avenue for our future research. We should also test theoretical models, including the one we developed to explain the Australian case, using rich empirical data. ${ }^{25}$ We believe that such comparative and empirical studies will improve our understandings of previously under-investigated but important decisions by political parties - their "personnel strategies."

\footnotetext{
${ }^{25}$ Such investigations require data on "second-best" candidates who did not run for general elections (as they had lost in primaries or had not been selected in informal selection processes. To the best of our knowledge, such data were not yet systematically collected by political scientists.
} 


\section{References}

Adams, James and Samuel Merrill. 2008. "Candidate and Party Strategies in Two-Stage Elections Beginning with a Primary." American Journal of Political Science 52(2):344359.

Allan, Lyle. 2002. "ALP Modernisation, Ethnic Branch Stacking, Factionalism and the Law." People and Place 10(4):50-58.

Ansolabehere, Stephen, James M. Snyder and Charles Stewart. 2000. "Old Voters, New Voters, and the Personal Vote: Using Redistricting to Measure the Incumbency Advantage." American Journal of Political Science 44(1):17-34.

Carey, John M. and John Polga-Hecimovich. 2006. "Primary Elections and Candidate Strength in Latin America." The Journal of Politics 68(3):530-543.

Carson, Jamie L. 2005. "Strategy, Selection, and Candidate Competition in U.S. House and Senate Elections." The Journal of Politics 67(1):1-28.

Carson, Jamie L., Erik J. Engstrom and Jason M. Roberts. 2007. "Candidate Quality, the Personal Vote, and the Incumbency Advantage in Congress." American Political Science Review 101(02):289-301.

De Luca, Miguel, Mark P. Jones and María Inés Tula. 2002. "Back Rooms or Ballot Boxes? Candidate Nomination in Argentina." Comparative Political Studies 35(4):413 -436.

Galasso, Vincenzo and Tommaso Nannicini. 2011. "Competing on Good Politicians." American Political Science Review 105(01):79-99.

Gallagher, Michael and Michael Marsh, eds. 1988. Candidate Selection in Comparative Perspective: The Secret Garden of Politics. London; Newbury Park, CA: Sage Publications. 
Gelman, Andrew and Gary King. 1990. "Estimating Incumbency Advantage without Bias." American Journal of Political Science 34(4):1142-1164.

Gerber, Elisabeth R. and Rebecca B. Morton. 1998. "Primary election systems and representation." Journal of Law, Economics, and Organization 14(2):304-324.

Horiuchi, Yusaku and Meg Sato. 2010. "Electoral Redistricting, Incumbency Advantage, and Endogenous Candidate Selection." Working Paper.

Jaensch, Dean. 1983. The Australian Party System. Sydney: George Allen \& Unwin.

Jaensch, Dean. 2006. Party Structures and Procedures. In Political Parties in Transition, ed. Ian Marsh. Sydney: Federation Press.

Kemahlioglu, Ozge, Rebecca Weitz-Shapiro and Shigeo Hirano. 2009. "Why Primaries in Latin American Presidential Elections?" The Journal of Politics 71(01):339-352.

Kenney, Patrick J. and Tom W. Rice. 1987. "The Relationship between Divisive Primaries and General Election Outcomes." American Journal of Political Science 31(1):31-44.

Levitt, Steven D. and Catherine D. Wolfram. 1997. "Decomposing the Sources of Incumbency Advantage in the U. S. House." Legislative Studies Quarterly 22(1):45-60.

Miller, Michael K. 2011. "Seizing the Mantle of Change: Modeling Candidate Quality as Effectiveness instead of Valence." Journal of Theoretical Politics 23(1):52 -68.

Sawer, Marian, Norman Abjorensen and Philip Larkin. 2009. Australia: The State of Democracy. Annandale, NSW, Australia: Federation Press.

Schantz, Harvey L. 1980. "Contested and Uncontested Primaries for the U. S. House." Legislative Studies Quarterly 5(4):545-562. 
Serra, Gilles. 2011. "Why Primaries? The Party's Tradeoff between Policy and Valence." Journal of Theoretical Politics 23(1):21 -51.

West, Darrell M. and John M. Orman. 2002. Celebrity Politics. 1 ed. Upper Saddle River, NJ: Prentice Hall. 